\title{
Quantitative assessment of the association between APC promoter methylation and breast cancer
}

\author{
Keli He ${ }^{1,2}$, Li Zhang ${ }^{1}$, Xinghua Long ${ }^{1}$ \\ ${ }^{1}$ Zhongnan Hospital of Wuhan University, Wuhan, 430071, China \\ ${ }^{2}$ Department of Clinical Laboratory, The First People's Hospital of Changde City, Changde, 415003, China \\ Correspondence to: Xinghua Long, email: zhoulongxinghua@qq.com
}

Keywords: adenomatous polyposis coli, APC, methylation, meta-analysis, breast cancer

Received: January 13, 2016

Accepted: April 26, 2016

Published: May 13, 2016

\section{ABSTRACT}

Adenomatous polyposis coli (APC) is an important tumor suppressor gene in breast cancer. However, there were inconsistent conclusions in the association between APC promoter methylation and breast cancer. Hence, we conducted a meta-analysis to quantitatively assess the clinicopathological significance and diagnosis role of APC methylation in breast cancer. In total, 3172 samples from 29 studies were performed in this study. The odds ratio (OR) of APC methylation was 5.92 (95\% CI = 3.16-11.07) in breast cancer cases compared to controls,. The APC promoter methylation was associated with cancer stage $(O R=0.47,95 \% C I=0.28-0.80, P=0.006)$, lymph node metastases (OR $=0.55,95 \% \mathrm{CI}=0.36-0.84, P=0.005)$ and $E R$ status $(\mathrm{OR}=1.34,95 \% \mathrm{CI}=1.03-1.73, P=0.003)$ in breast cancer. Furthermore, the sensitivity and specificity for all included studies were 0.444 ( $95 \%$ CI: $0.321-0.575$, $P<0.0001)$ and 0.976 (95\% CI: $0.916-0.993, P<0.0001)$, respectively. These results suggested that APC promoter methylation was associated with breast cancer risk, and it could be a valuable biomarker for diagnosis, treatment and prognosis of breast cancer.

\section{INTRODUCTION}

Breast cancer is the first leading cause of cancerrelated death among women $[1,2]$. In worldwide, approximately 1.3 million women were diagnosed with breast cancer each year [2]. As we know that breast cancer onset and progression are caused by a series of epigenetic and genetic changes. DNA methylation is a commonly observed epigenetic modification in human malignancies $[3,4]$. Methylation in tumor suppressor gene is one of the most common methylation, in cancer, including breast cancer $[5,6]$. Therefore, it is important to identify the role of suppressor genes methylation in breast cancer and gain a better understanding of the underlying pathogenesis of breast cancer.

The adenomatous polyposis coli (APC) gene located at chromosomal band $5 \mathrm{q} 21-\mathrm{q} 22$ is a classical tumor suppressor gene [7]. APC inactivation leads to dysfunction of $\beta$-catenin protein degradation, and then activates Tcf/Lef and causes abnormal transcription of oncogenens, such as c-myc, c-jun and cyclin D1, finally leads to carcinogenesis [8]. Methylation in APC gene has been investigated in several types of malignancies, including colorectal cancer [9], prostate cancer [10], hepatocellular carcinoma [11], and breast cancer [12]. Even though there were lots of investigations, the relationships between APC promoter methylation and breast cancer are still controversial. Z Jin [12] and Masaru Shinozaki [13] thought APC methylation was related to breast cancer $(p<0.05)$, but So Yeon Park [14] and Susan R. Sturgeon [15] thought APC methylation had no relationship with breast cancer $(P>0.05)$. Therefore, we preformed a meta-analysis to quantitatively assess the association of APC promoter methylation with breast cancer risk and the clinical characteristics observed in breast cancer patients. Additionally, we comprehensively evaluated the diagnostic value of APC methylation for breast tumors, in order to provide evidence for the future application of APC in the prevention, diagnosis and treatment of breast cancer.

\section{RESULTS}

Identification of relevant studies

A total of 29 eligible studies were included in the pooled analyses based on the search method as described above [12, 14-42]. As the studies by Auwera (2009 and 
2010) and Hoque (2006 and 2009) investigated the patients from different cities, we did not exclude them. The flow chart in Figure 1 summarized the study selection process.

\section{Study characteristics}

A total of 3172 samples from 29 articles were performed in this meta-analysis. Among 29 studies, there were 26 case-control studies [12, 14, 15-33, 35, 37-40] and 3 cohort studies [35, 36, 41]. Interestingly, 12 studies $[12,14,15,18,19,22,24,26-28,32,38]$ among 26 casecontrol studies also did the cohort analyses. Therefore, there were 26 case-control studies for the relationship of APC promoter methylation and breast cancer risk, and 15 cohort studies related with the association between APC methylation and clinicopathological characteristics of breast cancer. The major characteristics of the studies included in this meta-analysis were shown in Table 1.

\section{Association between APC promoter methylation and breast cancer risk}

In this study, we found that the frequency of APC methylation was significantly higher in breast cancer than normal controls. The pooled OR from 26 studies including 2073 breast cancers and 1164 controls was 5.92 with 95\% CI: 3.16-11.07 (Figure 2). With significant heterogeneity across the included studies $\left(I^{2}=77 \%\right)$, the stratification analyses of this meta-analysis were performed based on methods for detecting methylation, control types and ethnicities. In the stratified analysis by method, significantly increased breast cancer risk was associated with APC methylation by both QMSP method (OR $=3.11,95 \% \mathrm{CI}=1.72$ $5.62, P=0.0002)$ and MSP method $(\mathrm{OR}=13.38,95 \%$ $\mathrm{CI}=4.34-41.25, P<0.00001)$. Stratified analysis by control type showed that significantly increased risk was associated with APC methylation in tissue samples $(\mathrm{OR}=4.56,95 \% \mathrm{CI}=2.63-7.90, P<0.00001)$, and blood samples $(\mathrm{OR}=7.42,95 \% \mathrm{CI}=1.55-35.48$, $P=0.01)$. For stratified analysis by ethnicity, the APC methylation showed statistically significant association with increased risks of breast cancers in Caucasians $(\mathrm{OR}=3.08,95 \% \mathrm{CI}=1.92-4.96, P<0.00001)$ and in non-Caucasians $(\mathrm{OR}=18.75,95 \% \mathrm{CI}=4.12-85.28$, $P<0.00001)$. Details are shown in Table 2 .

\section{Association between APC prompter methylation and breast cancer clinicopathological characteristics}

We analyzed 2293 samples from 15 studies to assess whether the abnormal APC methylation was associated with breast cancer clinicopathological characteristics, including cancer stage, cancer grade, lymph node metastasis, menopausal status, ER status, PR status and HER2 status. The result showed that the association between APC promoter methylation and cancer stage was significant (pooled $\mathrm{OR}=0.47,95 \%$ CI: $0.28-0.80$, $P=0.006$, Figure 3), and similar result existed in the association between APC promoter methylation and lymph node metastasis (pooled OR $=0.55,95 \%$ CI: 0.36 $0.84, P=0.005$, Figure 4), which both suggested that APC promoter methylation could inhibit the cancer growth and metastasis. However, we found that there was no significant association between APC promoter methylation and cancer grade (pooled OR $=1.06,95 \%$ CI: $0.66-1.71$, $P=0.81$, Figure 5). There was no relationship between menopausal status and APC promoter methylation in breast cancer (pooled $\mathrm{OR}=0.79,95 \% \mathrm{CI}$ : $0.60-1.03$, $P=0.08$, Figure 6 ). In analyses of ER, PR and HER-2, we demonstrated that there was an association between APC promoter methylation and ER (pooled OR $=1.34$, 95\% CI: $1.03-1.73, P=0.03$, Figure 7), inversely there was no relationship between APC methylation and breast cancer with $\mathrm{PR}^{+}$(pooled $\mathrm{OR}=0.91,95 \% \mathrm{CI}$ : $0.71-1.18$, $P=0.49$, Figure 8 ) and Her- $2^{+}$(pooled OR $=0.79,95 \%$ CI: 0.44-1.40, $P=0.42$, Figure 9), which was in consistent with the previous study by Sunami et al. [34].

\section{Association between APC promoter methylation and diagnosis of breast cancer}

The pooled sensitivity and specificity for all included studies were 0.444 (95\% CI: $0.321-0.575$, $P<0.0001)$ and 0.976 (95\% CI: 0.916-0.993, $P<0.0001)$ based on mix-model. The AUC was 0.81 (95\% CI: 0.77-0.84) (Figure 10), suggesting detecting APC methylation has a good diagnostic accuracy for breast cancers. In order to present more robust results on APC methylation as the detection marker, we conducted a subgroup analysis stratified by control type: the pooled OR of sensitivity and specificity for tissue sample group were 0.452 (95\% CI: $0.302-0.611, P<0.0001)$ and 0.982 (95\% CI: $0.885-0.998, P<0.0001$ ); the pooled OR of sensitivity and specificity for blood sample group were 0.429 (95\% CI: $0.232-0.651, P<0.0001)$ and 0.962 (95\% CI: $0.866-0.990, P<0.0001)$. The AUC in all samples, tissue samples and blood samples analysis was $0.81,0.79$ and 0.85 , which suggested that it is more appropriate to monitor the level of APC methylation in blood samples for the diagnosing breast cancers.

\section{Publication bias}

We conducted potential publication bias by using Begg's rank correlation. The result suggested that there was no publication bias in breast cancer group versus control group $(P=0.052)$. Begg's funnel plot was shown in Figure 11. 


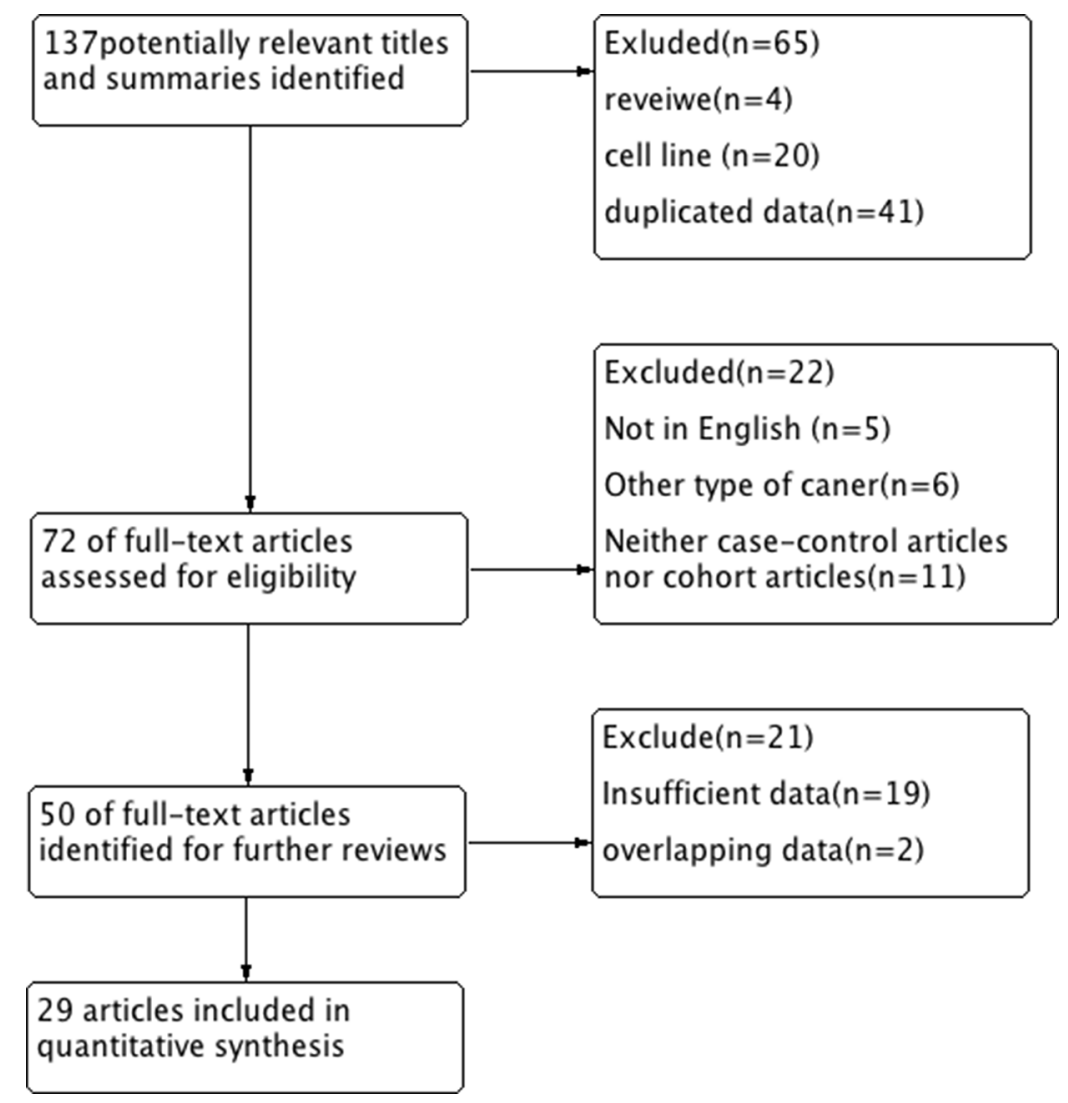

Figure 1: Flow diagram of the study selection process.

\section{DISCUSSION}

Breast cancer is a multiple steps, multiple phases, progressing procession of the tumourgenesis, and it is a type of gene disease involved in activation of oncogenes and inactivation of tumor suppressors [42]. As we know that APC is a tumor suppressor gene, which can be silenced or inactivated by methylation of $\mathrm{CpG}$ islands in gene promoter regions. Hence, we conducted a meta-analysis to investigate the association between breast cancer and APC methylation. Our data showed that the frequency of APC promoter methylation was demonstrated to be 5.92-fold high in breast cancer patients compared with non-breast cancer groups. The result was consistent with previous studies [12, 20-22, $24,25,43]$, which indicated that promoter methylation of APC could be implicated in the occurrence of breast tumors. Owing to the evident heterogeneity, we conducted stratification analyses based on methylation test method, control type and ethnicity. Finally we found that the value of $I^{2}$ was reduced in all stratified analyses, which suggested that test method, control type and ethnicity could lead to the heterogeneity. To date, it has become apparent that biomarkers were associated with cancer clinicopathological characteristics [44-46]. In this metaanalysis, we revealed that the frequency of APC promoter methylation increased in advanced TNM stage and lymph node metastasis breast cancer but decreased in ER positive breast cacner. TNM stage and lymph node metastasis were two of the most important prognostic factors for breast cancer. As is known to all that the prognosis of patients can be greatly improved by endocrine therapy, and $\mathrm{ER}^{+}$ breast cancer patients have good response to hormonal therapy [47]. Therefore, we inferred that APC promoter methylation might be contribute to the corresponding biology and clinical outcome of breast cancer.

This meta-analysis showed that pooled sensitivity and specificity for all included studies were 0.444 and 0.976 respectively, suggesting that the APC promoter methylation is a valuable biomarker for diagnosis of breast cancer. The summary results of sensitivity and specificity were objective and easy to understand, but they were often affected by different threshold value. The SROC curve is a synthesized index that includes two indexes that reflect the accuracy of diagnostic test (sensitivity and specificity). Additionally, the SROC curve makes the location results much more accurate and scientific by considering the non-linear relation between the sensitivity and specific. Furthermore, the SROC curve can compare the diagnostic test through graph and AUC. The AUC close to 1.0 signifies that the test has almost perfect discrimination while an AUC close to 0.5 suggest poor discrimination in this study AUC in this study was 0.82 . This was suggesting a good diagnostic accuracy of APC promoter methylation 
Table 1: Characteristics of studies included in the meta-analysis

\begin{tabular}{|c|c|c|c|c|c|c|c|c|c|}
\hline Study & Year & Country & Ethnicity & Case & & Control & & Control type & Method \\
\hline & & & & M & UM & M & UM & & \\
\hline Auwera et al. 2 & 2009 & Belgium & Caucasian & 23 & 56 & 1 & 18 & Blood & QMSP \\
\hline Auwera et al. & 2010 & Belgium & Caucasian & 31 & 25 & 20 & 36 & Tissue & QMSP \\
\hline Brooks & 2010 & USA & Mix & 1 & 49 & 6 & 142 & Blood & QMSP \\
\hline Cho et al. & 2010 & USA & Caucasian & 21 & 19 & 12 & 15 & Tissue & QMSP \\
\hline Dulaimi et al. & 2004 & USA & Caucasian & 15 & 19 & 0 & 12 & Tissue & MSP \\
\hline Hoque et al. & 2006 & Senegal & Africa & 14 & 79 & 0 & 38 & Blood & QMSP \\
\hline Hoque et al. & 2009 & Italy & Caucasian & 56 & 56 & 0 & 32 & Tissue & QMSP \\
\hline Jeronino et al. & 2008 & Portugal & Caucasian & 55 & 11 & 30 & 13 & Tissue & QMSP \\
\hline Jin et al. & 2001 & Japan & Asia & 18 & 32 & 0 & 21 & Tissue & MSP \\
\hline Jing et al. & 2010 & China & Asia & 14 & 36 & 0 & 50 & Blood & MSP \\
\hline Jung et al. & 2013 & Korea & Asia & 19 & 41 & 0 & 60 & Tissue & QMSP \\
\hline Lee et al. & 2004 & Korea & Asia & 14 & 18 & 0 & 19 & Tissue & MSP \\
\hline Lewis et al. & 2005 & USA & Caucasian & 15 & 12 & 23 & 59 & Tissue & MSP \\
\hline Martins et al. & 2011 & Portugal & Caucasian & 144 & 34 & 18 & 15 & Tissue & QMSP \\
\hline Matusckek et al. & 2010 & Germany & Caucasian & 25 & 60 & 2 & 22 & Blood & QMSP \\
\hline Müller et al. & 2003 & Austria & Caucasian & 6 & 20 & 0 & 10 & Blood & QMSP \\
\hline Pang et al. & 2014 & Australian & Caucasian & 39 & 41 & 0 & 18 & Tissue & QMSP \\
\hline Park et al. & 2011 & Korea & Asia & 31 & 54 & 2 & 28 & Tissue & QMSP \\
\hline Parrela et al. & 2004 & Italy & Caucasian & 11 & 43 & 1 & 9 & Tissue & MSP \\
\hline Prasad et al. & 2008 & India & Caucasian & 6 & 26 & 0 & 5 & Tissue & MSP \\
\hline Rykova et al. & 2006 & Russian & Caucasian & 4 & 6 & 0 & 6 & Blood & MSP \\
\hline Shinozak et al. & 2005 & USA & Caucasian & 74 & 77 & 0 & 10 & Tissue & MSP \\
\hline Sturgeon et al. & 2012 & USA & Caucasian & 9 & 236 & 10 & 186 & Blood & QMSP \\
\hline Sunami et al. & 2008 & USA & Caucasian & 51 & 14 & - & - & - & MSP \\
\hline Swellam et al. & 2015 & Egypt & Africa & 113 & 8 & 6 & 70 & Blood & MSP \\
\hline Virmani et al. & 2001 & USA & Caucasian & 34 & 43 & 3 & 28 & Tissue & MSP \\
\hline Wojdacz et al. & 2011 & Denmark & Caucasian & 23 & 157 & 13 & 95 & Blood & QMSP \\
\hline $\mathrm{Xu}$ et al. & 2010 & USA & Mix & 412 & 439 & - & - & - & QMSP \\
\hline Tserga et al. & 2012 & Greece & Caucasian & 22 & 27 & - & - & - & QMSP \\
\hline
\end{tabular}

M, methylation; UM unmethylation; MSP, Methylation-Specific PCR; QMSP, Quantitative real time Methylation Specific.

in breast cancer. However, APC promoter methylation may not be suitable for screening and diagnosing breast cancer alone due to the low sensitivity $(\mathrm{OR}=0.444)$. The SROC curve in this meta-analysis showed that there was great difference in the sensitivity, suggesting that the results of sensitivity were unstable according to the way of the method and the experimental ability of investors. Therefore, continuously improving the experimental processes and methods may improve the sensitivity. Blood sample test is non-invasive and promising for clinical application because it is more acceptable to patients. In our analysis the AUC in blood sample test was the highest, indicating blood sample may be considered as the priority sample in the clinical application.
However, some limitations need to be discussed. Firstly, even though the heterogeneity decreased by subgroup analysis, it was still high. The difference of methylation detection primers may be one of the reasons. However we can't get enough information about the processes of detecting APC methylation from the included studies. Secondly, articles published in English were only included in this meta-analysis. We could have missed the articles published in other languages, because of anticipated difficulties in obtaining accurate medical translation. Thirdly, we did not retrieve articles related with APC methylation in different subtypes of breast cancer. Further studies should be needed to investigate the frequency of APC methylation in breast cancer types. 
Finally, there was low sensitivity for APC methylation to detect breast tumors. The reason is that a single tumor marker has limited power to diagnose breast cancers that implicate various genes and other factors. It is necessary to mention that the combination of several tumor makers can improve the sensitivity and specificity of diagnosis test for tumors. For instance, Brooks et al. [16] found that the diagnosis in combination with RASSF1A, GSTP1, RARb2, and APC methylation can significantly improve the detection of breast cancer.

In conclusion, this was the first meta-analysis about APC promoter methylation and breast cancer. The current evidence suggested that APC promoter methylation was associated with breast cancer risk and clinicopathological characteristics. In addition, APC promoter methylation was a valuable diagnostic biomarker with high specificity and qualified sensitivity. Well-designed prospective studies with larger sample sizes will help in further strengthening our observations.

\section{MATERIALS AND METHODS}

\section{Search strategy and selection criteria}

PubMed, EMBASE, and Cochrane Library were searched up to December 2015 using the key words "APC", "methylation" and "breast cancer". We also retrieved the reference lists of the articles identified in the searches for additional eligible studies. Studies included in the meta-analysis had to meet all the following criteria (1) the case-control or cohort studies assessing the association of APC methylation and breast cancer, (2) studies providing sufficient information to estimate odds ratio (OR) and 95\% confidence interval (CI), (3) articles were published in English. The major reasons for exclusion of studies were (1) reviews, letter or caseonly articles and (2) articles with insufficient data or duplicated data.

\section{Data extraction}

Two investigators reviewed all of articles that fitted inclusion and exclusion criteria and independently extracted data from eligible studies. Disagreement was resolved by discussion and consensus. Data retrieved from the reports included author, year, country, ethnicity, control type, method for detecting methylation, clinicopathological characteristics, and number of methylated (M) and unmethylated (U) samples in cases and controls. We chose only one study with the largest sample size and the most detailed information when multiple reports were published from the same study population.

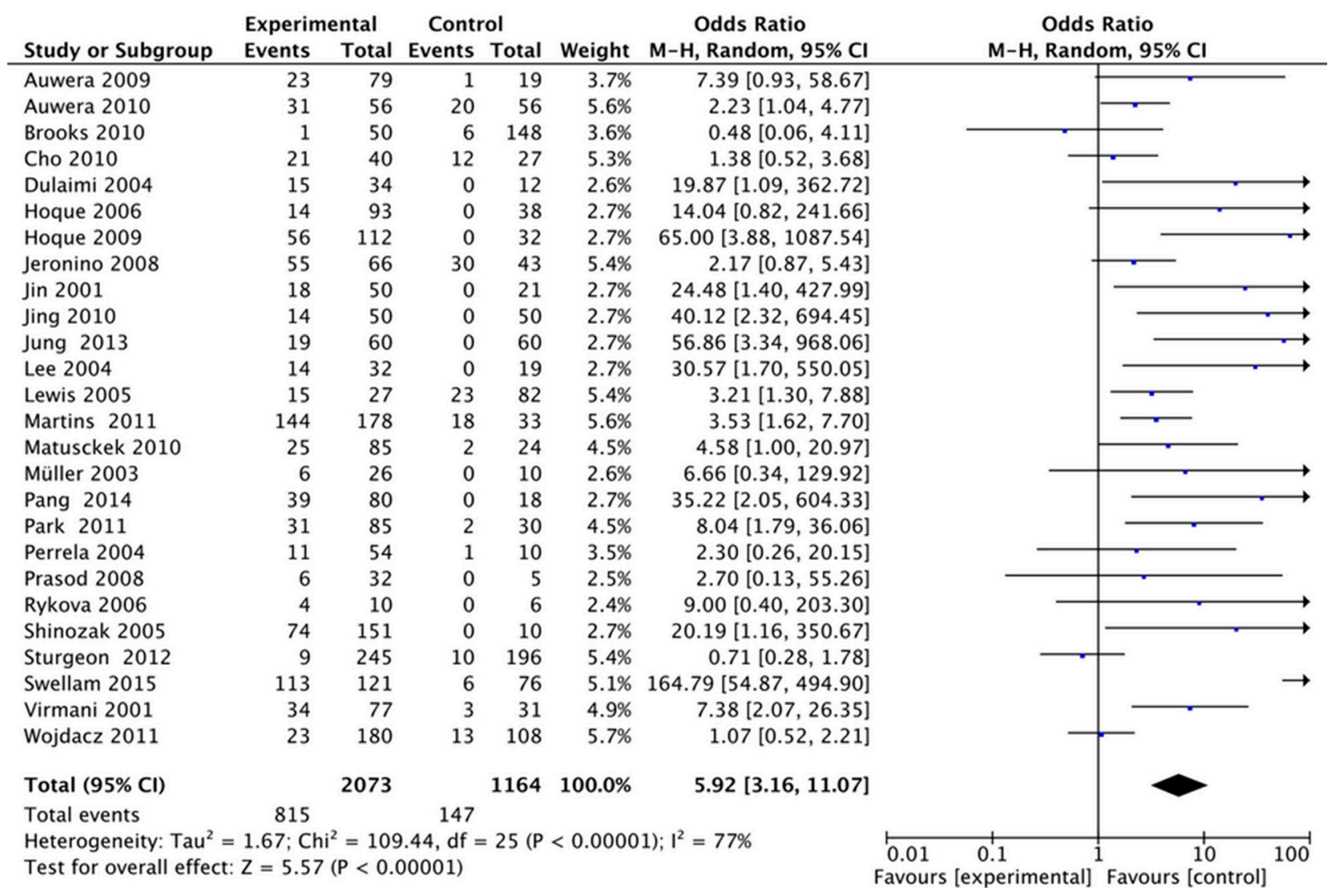

Figure 2: Forest plots of association between APC promoter methylation and breast cancer. 
Table 2: Subgroup analysis APC promoter methylation in breast cancer

\begin{tabular}{|l|c|c|c|c|c|c|c|c|}
\hline \multicolumn{3}{c}{ Case } & \multicolumn{3}{c}{ Control } & \multicolumn{1}{c}{ OR [95\% CI] } & \multicolumn{1}{c|}{ P $(\%)$} & Model \\
\hline & M & UM & M & UM & & & \\
\hline Total & 815 & 1258 & 147 & 1017 & $5.92[3.16,11.07]$ & $<0.00001$ & 77 & Random \\
\hline Method & & & & & & & & \\
\hline MSP & 318 & 320 & 33 & 316 & $13.38[4.34,41.25]$ & $<0.00001$ & 72 & Random \\
\hline QMSP & 497 & 938 & 114 & 728 & $3.11[1.72,5.62]$ & 0.0002 & 65 & Random \\
\hline Ethnicity & & & & & & & & \\
\hline Caucasian & 591 & 941 & 133 & 589 & $3.08[1.92,4.96]$ & $<0.00001$ & 52 & Random \\
\hline non-Caucasian & 224 & 317 & 14 & 428 & $18.75[4.12,85.28]$ & $<0.0001$ & 75 & Random \\
\hline Control type & & & & & & & & \\
\hline Blood & 231 & 667 & 32 & 495 & $7.42[1.55,35.48]$ & 0.01 & 89 & Random \\
\hline Tissue & 584 & 600 & 115 & 522 & $4.56[2.63,7.90]$ & $<0.00001$ & 52 & Random \\
\hline
\end{tabular}

M, methylation; UM unmethylation; MSP, Methylation-Specific PCR; QMSP, Quantitative real time Methylation Specific.

\section{Statistical analysis}

Meta-analysis was preformed by Review Manager Software 5.2 (Cochrane Collaboration, Oxford, UK) and STATA software 11.0 (STATA Corp., College Station, TX, USA). OR with the $95 \% \mathrm{CI}$ were used to examine differences in the frequency of APC methylation between breast cancer case and controls. The associations between APC methylation and breast cancer clinicopathological characteristics were also examined by the method. Data were extracted from the original studies and recalculated if necessary. $P$-value $<0.05$ was considered to be statistically significant.

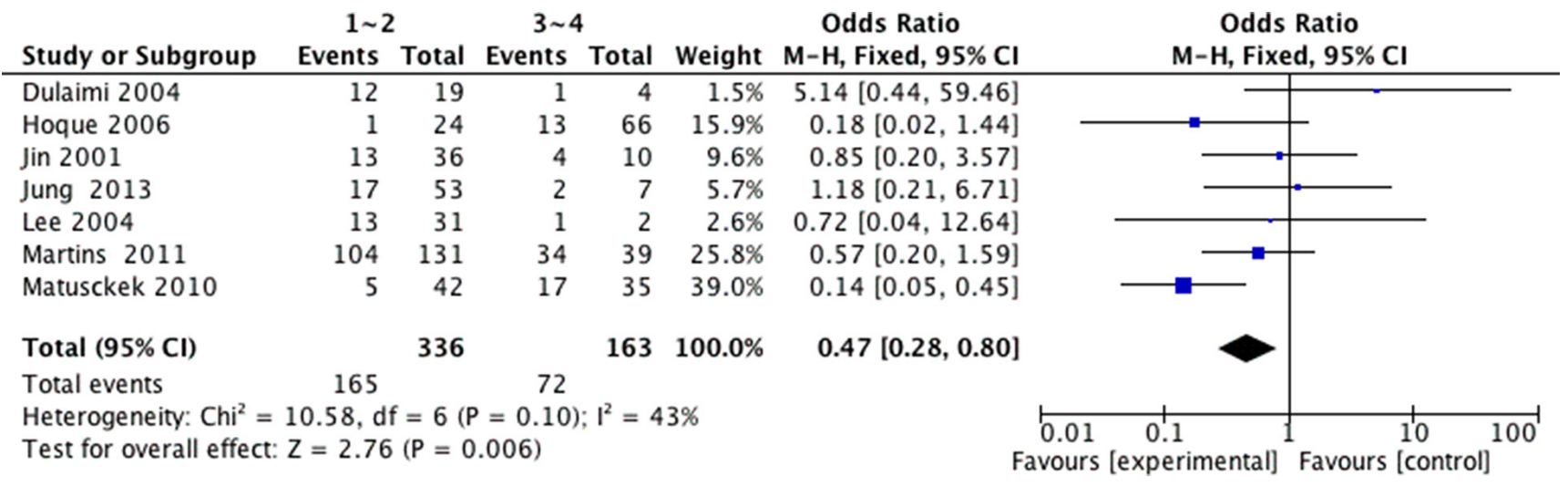

Figure 3: Forest plots of association between APC promoter methylation and cancer stage in breast cancer.

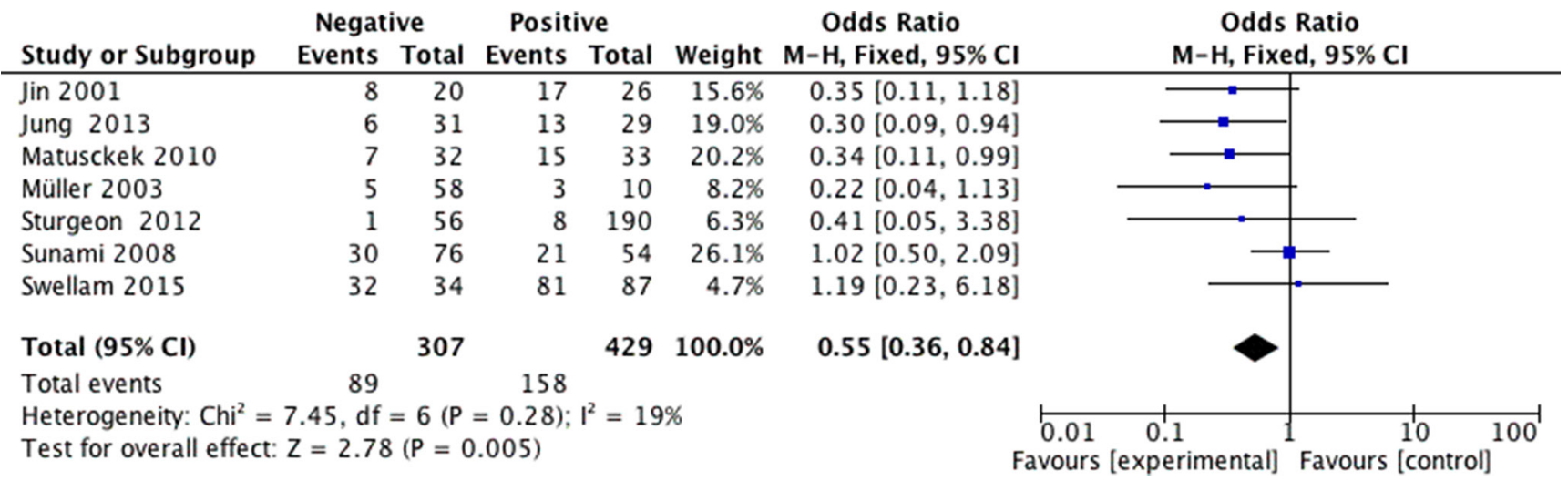

Figure 4: Forest plots of association between APC promoter methylation and lymph node metastasis in breast cancer. 
We used the sensitivity and specificity to estimate the diagnostic value of APC promoter methylation in breast cancer. However, the variation in the threshold definition of a positive result sometimes could produce an association between sensitivity and specificity values across studies. Thus we also constructed the summary receiver operator characteristic (SROC) curve that based on the sensitivity and specificity of each publication and calculated area under the SROC curve (AUC) to explore the diagnostic accuracy of APC methylation for breast cancer [48].

The heterogeneity among studies was checked with the Chi-square based on Q statistical test and $I^{2} . P \leq 0.1$ or $I^{2}>50 \%$ indicated significant heterogeneity among the studies and the pooled OR was estimated by the random-effects model (Mantel-Haenszel method). If the

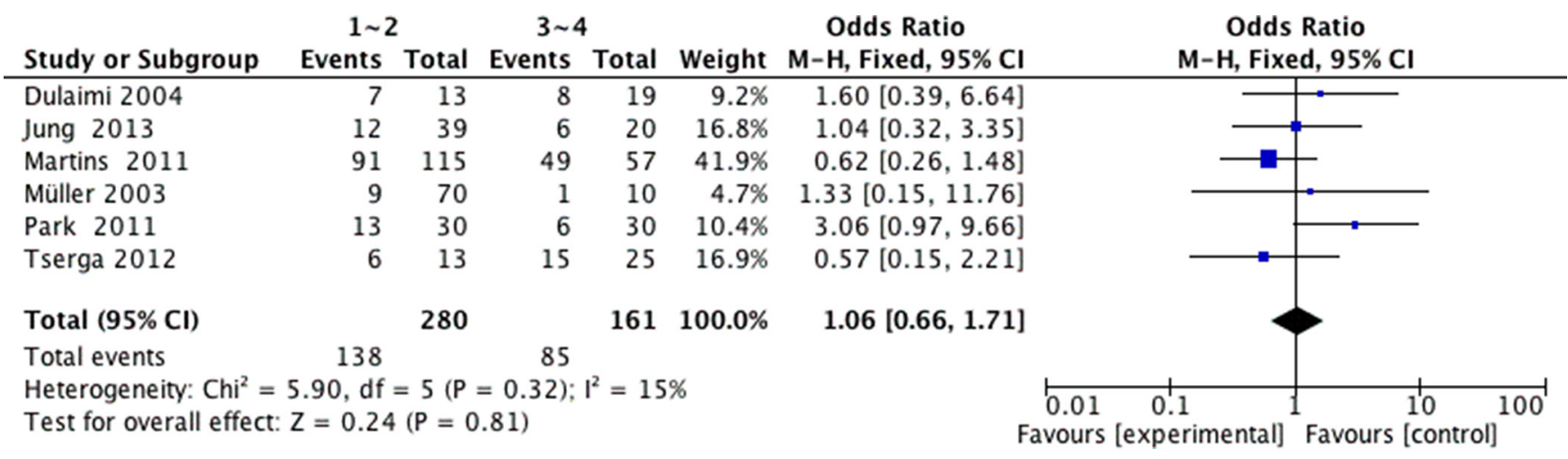

Figure 5: Forest plots of association between APC promoter methylation and cancer grade in breast cancer.

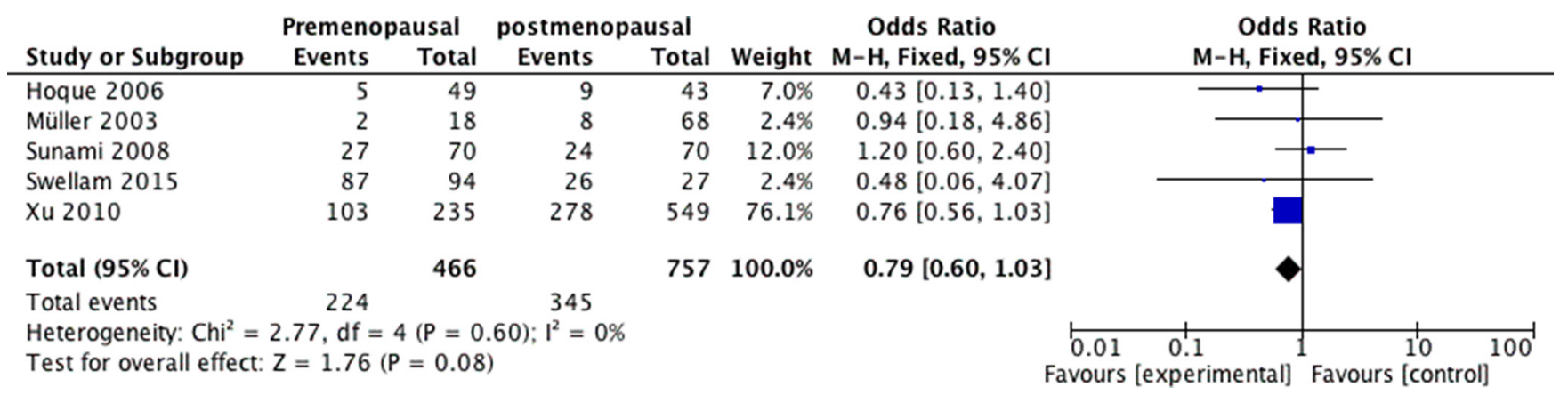

Figure 6: Forest plots of association between APC promoter methylation and menopausal status in breast cancer.

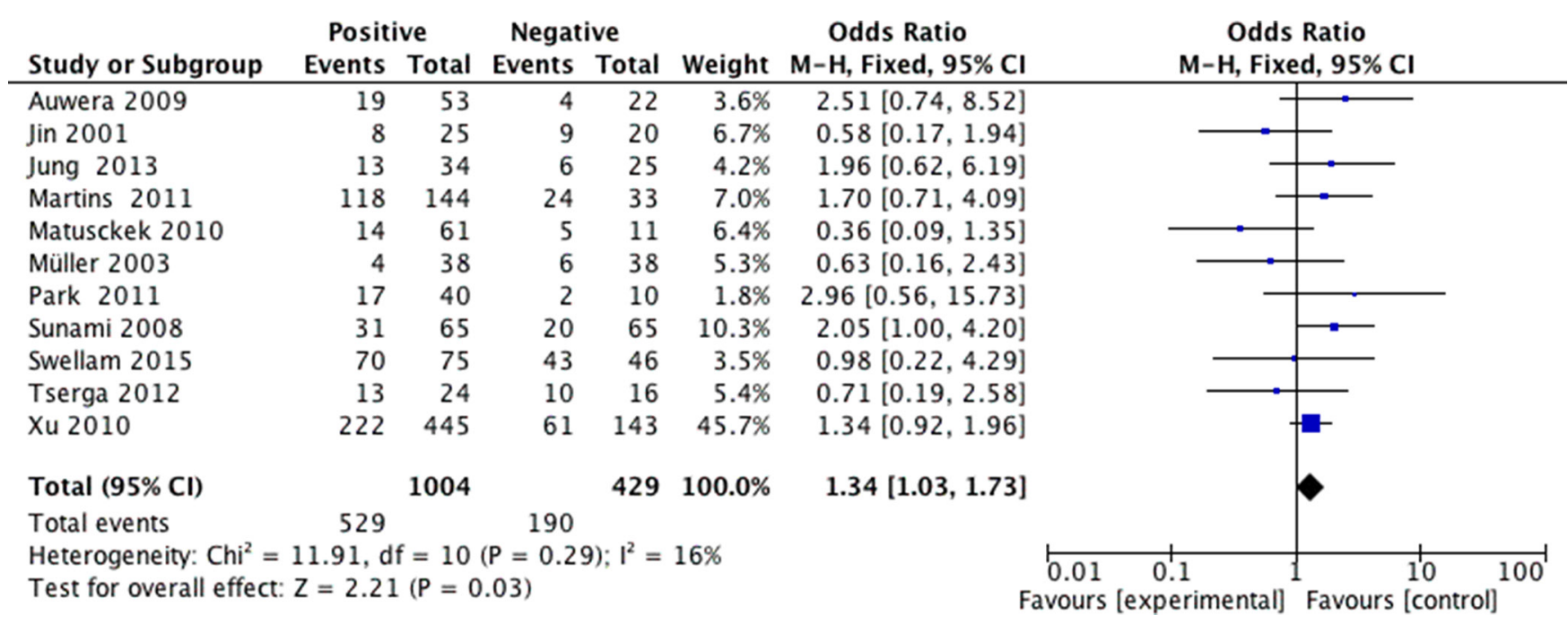

Figure 7: Forest plots of association between APC promoter methylation and ER status in breast cancer. 


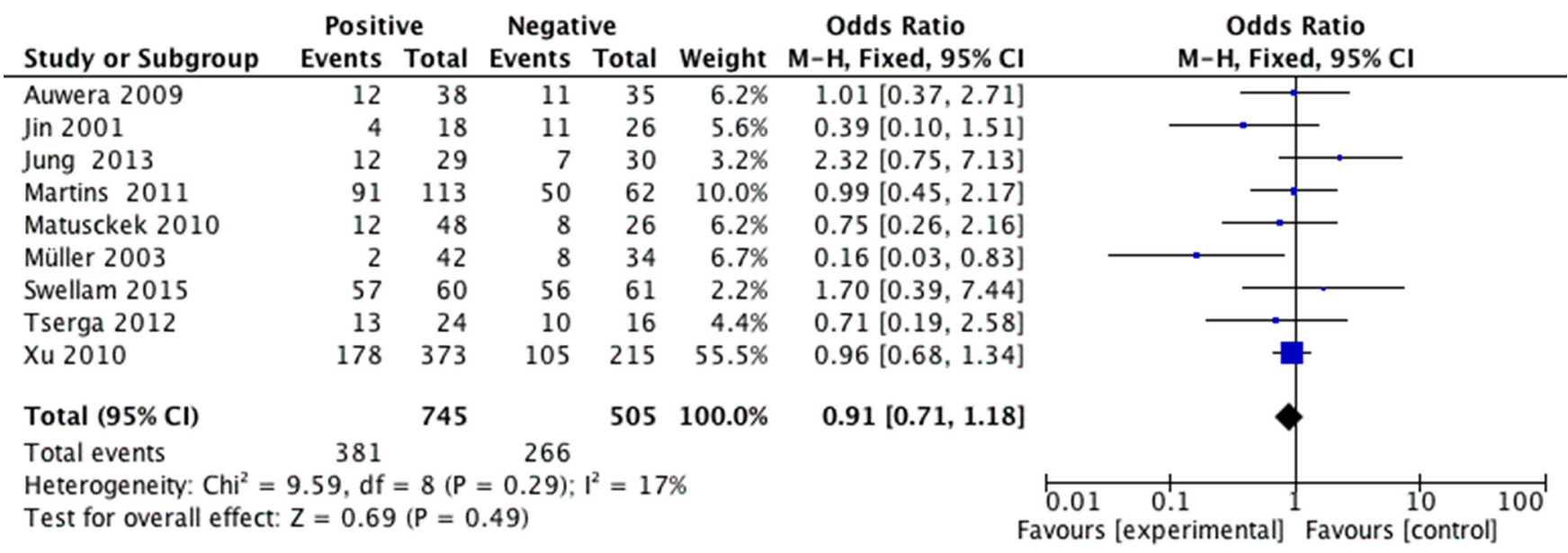

Figure 8: Forest plots of association between APC promoter methylation and PR status in breast cancer.

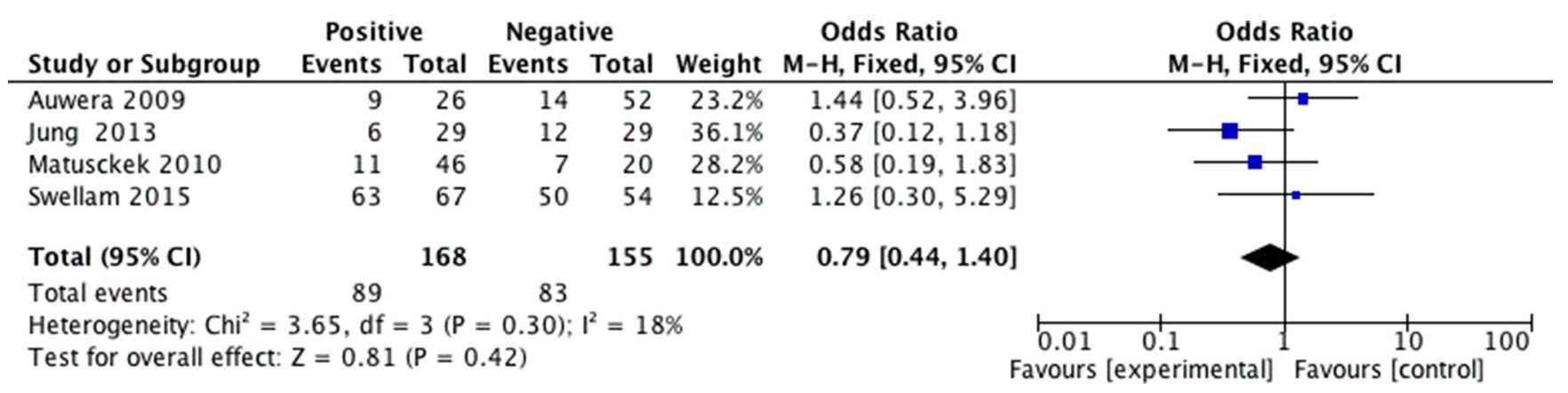

Figure 9: Forest plots of association between APC promoter methylation and HER-2 status in breast cancer.

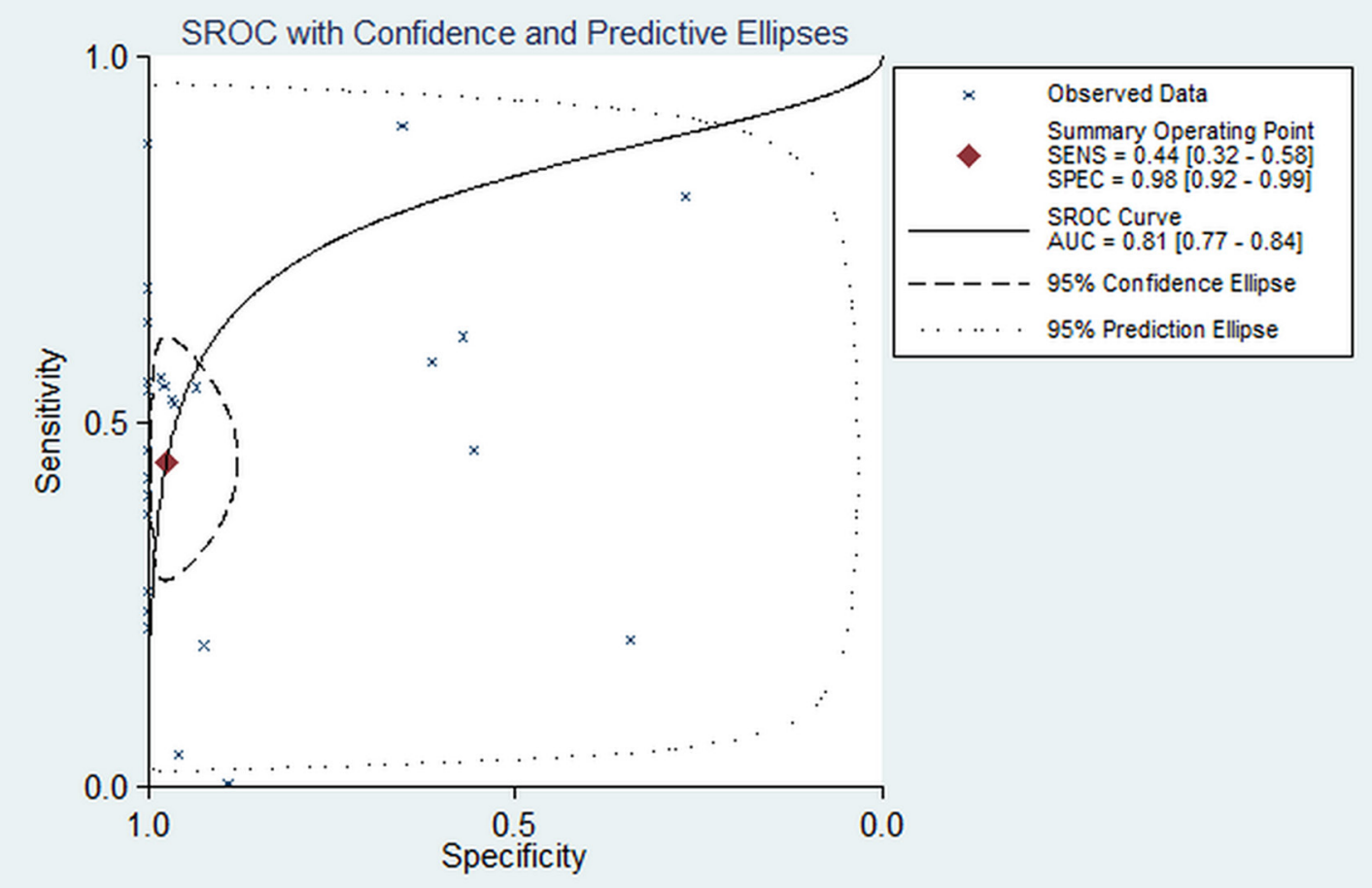

Figure 10: Meta-analysis with the S-ROC curve. SENS: Sensitivity, SPEC: Specificity, AUC: Area under the curve. 
Begg's funnel plot with pseudo $95 \%$ confidence limits

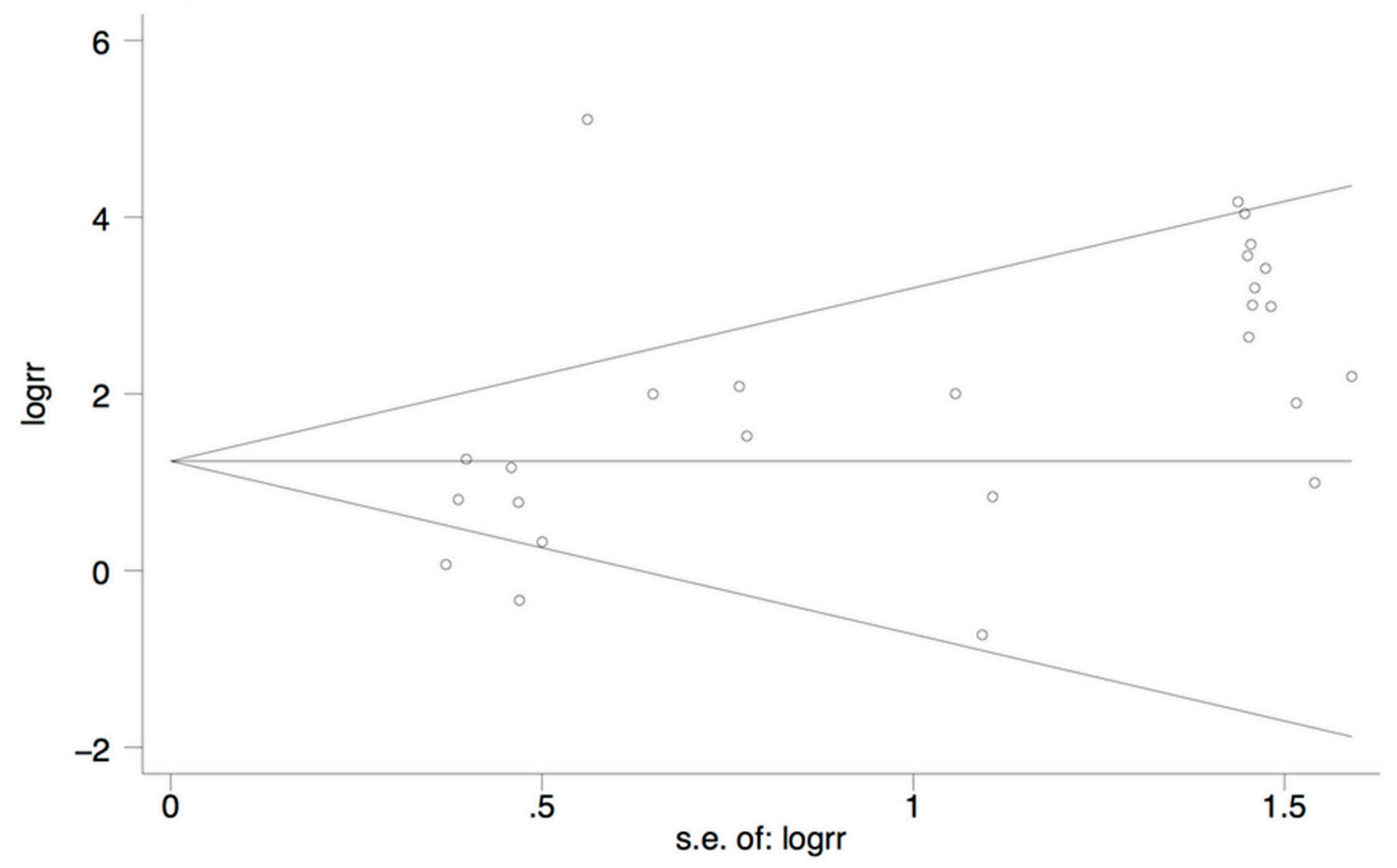

Figure 11: Begg's funnel plot for assessment of publication bias.

heterogeneity was in significant $\left(P \geq 0.1\right.$ or $\left.I^{2}<50 \%\right)$, the fixed-effects model (inverse variance method) was employed. Publication bias was assessed by Begg's rank correlation.

\section{ACKNOWLEDGMENTS AND FUNDING}

The Project-sponsored by SRF for ROCS, SEM. This work was supported by grants from National Natural Science Foundation of China (nos. 30873044 and 81272372 ).

\section{CONFLICTS OF INTEREST} interest.

The authors declare that they have no conflicts of

\section{REFERENCES}

1. Bray F, Ren JS, Masuyer E, Ferlay J. Global estimates of cancer prevalence for 27 sites in the adult population in 2008. Int J Cancer. 2013; 132:1133-1145.

2. Ferlay J, Soerjomataram I, Dikshit R, Eser S, Mathers C, Rebelo M, Parkin DM, Forman D, Bray F. Cancer incidence and mortality worldwide: sources, methods and major patterns in GLOBOCAN 2012. Int J Cancer. 2015; 136:E359-386.

3. Ghavifekr Fakhr M, Farshdousti Hagh M, Shanehbandi D, Baradaran B. DNA methylation pattern as important epigenetic criterion in cancer. Genet Res Int. 2013; 2013:317569.

4. Zhang L, Long X. Association of BRCA1 promoter methylation with sporadic breast cancers: Evidence from 40 studies. Sci Rep. 2015; 5:17869.

5. Ma X, Wang YW, Zhang MQ, Gazdar AF. DNA methylation data analysis and its application to cancer research. Epigenomics. 2013; 5:301-316.

6. Jones PA, Baylin SB. The fundamental role of epigenetic events in cancer. Nat Rev Genet. 2002; 3:415-428.

7. Polakis P. The adenomatous polyposis coli (APC) tumor suppressor. Biochim Biophys Acta. 1997; 1332:F127-147.

8. Fearnhead NS, Britton MP, Bodmer WF. The ABC of APC. Hum Mol Genet. 2001; 10:721-733.

9. Michailidi C, Theocharis S, Tsourouflis G, Pletsa V, Kouraklis G, Patsouris E, Papavassiliou AG, Troungos C. Expression and promoter methylation status of hMLH1, MGMT, APC, and CDH1 genes in patients with colon adenocarcinoma. Exp Biol Med (Maywood). 2015; 240:1599-1605.

10. Alkner S, Tang MH, Brueffer C, Dahlgren M, Chen Y, Olsson E, Winter C, Baker S, Ehinger A, Ryden L, Saal LH, Ferno M, Gruvberger-Saal SK. Contralateral breast cancer can represent a metastatic spread of the first primary tumor: determination of clonal relationship between contralateral breast cancers using next-generation whole genome sequencing. Breast Cancer Res. 2015; 17:102.

11. Xu B, Nie Y, Liu X, Feng S, Yang Z, Wang Z, Zheng Q, Luo X. Quantitative analysis of APC promoter methylation 
in hepatocellular carcinoma and its prognostic implications. Oncol Lett. 2014; 7:1683-1688.

12. Jin Z, Tamura G, Tsuchiya T, Sakata K, Kashiwaba M, Osakabe M, Motoyama T. Adenomatous polyposis coli (APC) gene promoter hypermethylation in primary breast cancers. Br J Cancer. 2001; 85:69-73.

13. Shinozaki M, Hoon DSB, Giuliano AE, Hansen NM, Wang HJ, Turner R, Taback B. Distinct hypermethylation profile of primary breast cancer is associated with sentinel lymph node metastasis. Clinical Cancer Research. 2005; 11:2156-2162.

14. Park SY, Kwon HJ, Lee HE, Ryu HS, Kim SW, Kim JH, Kim IA, Jung N, Cho NY, Kang GH. Promoter CpG island hypermethylation during breast cancer progression. Virchows Arch. 2011; 458:73-84.

15. Sturgeon SR, Balasubramanian R, Schairer C, Muss HB, Ziegler RG, Arcaro KF. Detection of promoter methylation of tumor suppressor genes in serum DNA of breast cancer cases and benign breast disease controls. Epigenetics. 2012; 7:1258-1267.

16. Brooks JD, Cairns P, Shore RE, Klein CB, Wirgin I, Afanasyeva Y, Zeleniuch-Jacquotte A. DNA methylation in pre-diagnostic serum samples of breast cancer cases: results of a nested case-control study. Cancer Epidemiol. 2010; 34:717-723.

17. Cho YH, Yazici H, Wu HC, Terry MB, Gonzalez K, Qu M, Dalay N, Santella RM. Aberrant promoter hypermethylation and genomic hypomethylation in tumor, adjacent normal tissues and blood from breast cancer patients. Anticancer Res. 2010; 30:2489-2496.

18. Dulaimi E, Hillinck J, Ibanez de Caceres I, AlSaleem T, Cairns P. Tumor suppressor gene promoter hypermethylation in serum of breast cancer patients. Clin Cancer Res. 2004; 10:6189-6193.

19. Hoque MO, Feng Q, Toure P, Dem A, Critchlow CW, Hawes SE, Wood T, Jeronimo C, Rosenbaum E, Stern J, Yu M, Trink B, Kiviat NB, et al. Detection of aberrant methylation of four genes in plasma DNA for the detection of breast cancer. J Clin Oncol. 2006; 24:4262-4269.

20. Hoque MO, Prencipe M, Poeta ML, Barbano R, Valori VM, Copetti M, Gallo AP, Brait M, Maiello E, Apicella A, Rossiello R, Zito F, Stefania T, et al. Changes in CpG islands promoter methylation patterns during ductal breast carcinoma progression. Cancer Epidemiol Biomarkers Prev. 2009; 18:2694-2700.

21. Jeronimo C, Monteiro P, Henrique R, Dinis-Ribeiro M, Costa I, Costa VL, Filipe L, Carvalho AL, Hoque MO, Pais I, Leal C, Teixeira MR, Sidransky D. Quantitative hypermethylation of a small panel of genes augments the diagnostic accuracy in fine-needle aspirate washings of breast lesions. Breast Cancer Res Treat. 2008; 109:27-34.

22. Jing F, Yuping W, Yong C, Jie L, Jun L, Xuanbing T, Lihua H. CpG island methylator phenotype of multigene in serum of sporadic breast carcinoma. Tumour Biol. 2010; 31 : $321-331$.
23. Jung EJ, Kim IS, Lee EY, Kang JE, Lee SM, Kim DC, Kim JY, Park ST. Comparison of methylation profiling in cancerous and their corresponding normal tissues from korean patients with breast cancer. Ann Lab Med. 2013; 33:431-440.

24. Lee A, Kim Y, Han K, Kang CS, Jeon HM, Shim SI. Detection of Tumor Markers Including Carcinoembryonic Antigen, APC, and Cyclin D2 in Fine-Needle Aspiration Fluid of Breast. Arch Pathol Lab Med. 2004; 128:1251-1256.

25. Lewis CM, Cler LR, Bu DW, Zochbauer-Muller S, Milchgrub S, Naftalis EZ, Leitch AM, Minna JD, Euhus DM. Promoter hypermethylation in benign breast epithelium in relation to predicted breast cancer risk. Clin Cancer Res. 2005; 11:166-172.

26. Martins AT, Monteiro P, Ramalho-Carvalho J, Costa VL, Dinis-Ribeiro M, Leal C, Henrique R, Jeronimo C. High RASSF1A promoter methylation levels are predictive of poor prognosis in fine-needle aspirate washings of breast cancer lesions. Breast Cancer Res Treat. 2011; 129:1-9.

27. Matuschek C, Bolke E, Lammering G, Gerber PA, Peiper M, Budach W, Taskin H, Prisack HB, Schieren G, Orth K, Bojar H. Methylated APC and GSTP1 genes in serum DNA correlate with the presence of circulating blood tumor cells and are associated with a more aggressive and advanced breast cancer disease. Eur J Med Res. 2010; 15:277-286.

28. Muller HM, Widschwendter A, Fiegl H, Ivarsson L, Goebel G, Perkmann E, Marth C, Widschwendter M. DNA methylation in serum of breast cancer patients: an independent prognostic marker. Cancer Res. 2003; 63:7641-7645.

29. Pang JM, Deb S, Takano EA, Byrne DJ, Jene N, Boulghourjian A, Holliday A, Millar E, Lee CS, O'Toole SA, Dobrovic A, Fox SB. Methylation profiling of ductal carcinoma in situ and its relationship to histopathological features. Breast Cancer Res. 2014; 16:423.

30. Parrella P, Poeta ML, Gallo AP, Prencipe M, Scintu M, Apicella A, Rossiello R, Liguoro G, Seripa D, Gravina C, Rabitti C, Rinaldi M, Nicol $T$, et al. Nonrandom distribution of aberrant promoter methylation of cancerrelated genes in sporadic breast tumors. Clin Cancer Res. 2004; 10:5349-5354.

31. Prasad CP, Mirza S, Sharma G, Prashad R, DattaGupta S, Rath G, Ralhan R. Epigenetic alterations of CDH1 and APC genes: relationship with activation of Wnt/beta-catenin pathway in invasive ductal carcinoma of breast. Life Sci. 2008; 83:318-325.

32. Rykova EY, Skvortsova TE, Laktionov PP, Tamkovich SN, Bryzgunova OE, Starikov AV, Kuznetsova NP, Kolomiets SA, Sevostianova NV, Vlassov VV. Investigation of tumor-derived extracellular DNA in blood of cancer patients by methylation-specific PCR. Nucleosides Nucleotides Nucleic Acids. 2004; 23:855-859.

33. Shinozaki M, Hoon DS, Giuliano AE, Hansen NM, Wang HJ, Turner R, Taback B. Distinct hypermethylation profile of primary breast cancer is associated with 
sentinel lymph node metastasis. Clin Cancer Res. 2005; 11:2156-2162.

34. Sunami E, Shinozaki M, Sim MS, Nguyen SL, Vu AT, Giuliano AE, Hoon DS. Estrogen receptor and HER2/neu status affect epigenetic differences of tumor-related genes in primary breast tumors. Breast Cancer Res. 2008; 10:R46.

35. Swellam M, Abdelmaksoud MD, Sayed Mahmoud M, Ramadan A, Abdel-Moneem W, Hefny MM. Aberrant methylation of APC and RARbeta2 genes in breast cancer patients. IUBMB Life. 2015; 67:61-68.

36. Tserga A, Michalopoulos NV, Levidou G, Korkolopoulou P, Zografos G, Patsouris E, Saetta AA. Association of aberrant DNA methylation with clinicopathological features in breast cancer. Oncology Reports. 2012; 27:1630-1638.

37. Van der Auwera I, Bovie C, Svensson C, Trinh XB, Limame R, van Dam P, van Laere SJ, van Marck EA, Dirix LY, Vermeulen PB. Quantitative methylation profiling in tumor and matched morphologically normal tissues from breast cancer patients. BMC Cancer. 2010; 10:97.

38. Van der Auwera I, Elst HJ, Van Laere SJ, Maes H, Huget P, van Dam P, Van Marck EA, Vermeulen PB, Dirix LY. The presence of circulating total DNA and methylated genes is associated with circulating tumour cells in blood from breast cancer patients. Br J Cancer. 2009; 100:1277-1286.

39. Virmani AK, Rathi A, Sathyanarayana UG, Padar A, Huang CX, Cunnigham HT, Farinas AJ, Milchgrub S, Euhus DM, Gilcrease M, Herman J, Minna JD, Gazdar AF. Aberrant methylation of the adenomatous polyposis coli (APC) gene promoter 1A in breast and lung carcinomas. Clin Cancer Res. 2001; 7:1998-2004.

40. Wojdacz TK, Thestrup BB, Cold S, Overgaard J, Hansen LL. No difference in the frequency of locusspecific methylation in the peripheral blood DNA of women diagnosed with breast cancer and age-matched controls. Future Oncology. 2011; 7:1451-1455.
41. Xu XR, Gammon MD, Zhang YJ, Cho YH, Wetmur JG, Bradshaw PT, Garbowski G, Hibshoosh H, Teitelbaum SL, Neugut AI, Santella RM, Chen J. Gene promoter methylation is associated with increased mortality among women with breast cancer. Breast Cancer Research and Treatment. 2010; 121:685-692.

42. Zhang L, Fang C, Xu X, Li A, Cai Q, Long X. Androgen receptor, EGFR, and BRCA1 as biomarkers in triplenegative breast cancer: a meta-analysis. Biomed Res Int. 2015; 2015:357485.

43. Dammann R, Yang G, Pfeifer GP. Hypermethylation of the cpG island of Ras association domain family $1 \mathrm{~A}$ (RASSF1A), a putative tumor suppressor gene from the 3 p21.3 locus, occurs in a large percentage of human breast cancers. Cancer Res. 2001; 61:3105-3109.

44. Zhong Q, Xi S, Liang J, Shi G, Huang Y, Zhang Y, Levy D, Zhong S. The significance of Brfl overexpression in human hepatocellular carcinoma. Oncotarget. 2016; 7:6243-54. doi: 10.18632/oncotarget.6668.

45. Wang F, Feng Y, Li P, Wang K, Feng L, Liu YF, Huang H, Guo YB, Mao QS, Xue WJ. RASSF10 is an epigenetically inactivated tumor suppressor and independent prognostic factor in hepatocellular carcinoma. Oncotarget. 2016; 7:4279-97. doi: 10.18632/oncotarget.6654.

46. Dalton WS, Friend SH. Cancer biomarkers - an invitation to the table. Science. 2006; 312:1165-1168.

47. Lumachi F, Santeufemia DA, Basso SM. Current medical treatment of estrogen receptor-positive breast cancer. World J Biol Chem. 2015; 6:231-239.

48. Deville WL, Buntinx F, Bouter LM, Montori VM, de Vet HC, van der Windt DA, Bezemer PD. Conducting systematic reviews of diagnostic studies: didactic guidelines. BMC Med Res Methodol. 2002; 2:9. 